\title{
Clinical Experience in the Treatment of Nephroptosis Using Retroperitoneal Laparoscopic Nephropexy
}

\author{
Ruojing Wei \\ Affiliated Hospital of Hebei University, Baoding, China \\ Email: 18630291058@163.com
}

Received 11 May 2014; revised 9 June 2014; accepted 16 June 2014

Copyright (C) 2014 by author and Scientific Research Publishing Inc. This work is licensed under the Creative Commons Attribution International License (CC BY). http://creativecommons.org/licenses/by/4.0/

(c) (i) Open Access

\section{Abstract}

Background: Retroperitoneal laparoscopic nephropexy has been applied to nephroptosis. We investigate the approach and treatment effect of retroperitoneal laparoscopic nephropexy. Methods: From May 1990 to October 2013, 45 patients with nephroptosis treated in our hospital were retrospectively analyzed. Among them, 25 patients underwent nephropexy (open surgery group), the other 20 patients underwent retroperitoneal laparoscopic nephropexy (laparoscopic surgery group). In open surgery group, there were 24 females and 1 male, aged 20 - 35 years. In laparoscopic surgery group, there were 19 females and 1 male, aged 20 - 35 years. All of them with nephroptosis of the right kidney were combined with lower back pain or hematuria and underwent intravenous pyelography (IVP) and color ultrasound in orthostatic and supine position for a specific diagnosis. In open surgery group, patients underwent open surgery. Their kidneys were fully dissociated, then, the upper and middle pole of the dorsal kidney was sutured with lumbar fascia for two stitches for fixation respectively. While in laparoscopic surgery group, kidneys were fully dissociated in Gerota's fascia during laparoscopic surgery, and the upper pole of the dorsal kidney was sutured with the lumbar fascia for two stitches using a 2-0 absorbable suture. They were all in the supine position for a week after surgery. The body mass index (BMI), operation time, bleeding amount, postoperative hospital stay, wound complication rate and other indicators were compared between two groups. Results: BMI in open surgery group was $16.77 \pm 0.80 \mathrm{~kg} / \mathrm{m}^{2}$, BMI in laparoscopic surgery group was $16.73 \pm 0.78 \mathrm{~kg} / \mathrm{m}^{2}, P>0.05$ showed no statistical difference; the operation time in open surgery group was $70.96 \pm 10.61 \mathrm{~min}$, that in laparoscopic surgery group was $34.65 \pm 4.87 \mathrm{~min}, P<0.001$ showed highly statistical significance; the bleeding amount in open surgery group was $20.65 \pm 6.48 \mathrm{ml}$, that in laparoscopic surgery group was $4.85 \pm 1.63 \mathrm{ml}, P<$ 0.001 showed highly statistical significance; the postoperative hospital stay in open surgery group was $7.54 \pm 1.28 \mathrm{~d}$, that in laparoscopic surgery group was $7 \mathrm{~d}, P>0.05$ showed no statistical difference. In open surgery group, four patients had wound infection which delayed the healing, and the wound complication rate was $16 \%(4 / 25)$. In laparoscopic surgery group, wound complica- 
tions did not appear, the incidence was $0 \%, \mathrm{X}^{2}=1.8144, P>0.05$ showed no statistical difference. The mean follow-up visit lasted 1.5 years after surgery ( 3 months to 2 years), B-mode ultrasound in orthostatic and supine position showed kidneys were in the normal position. Compared with those before surgery, postoperative uncomfortable symptoms completely disappeared in all patients. Conclusions: Retroperitoneal laparoscopic nephropexy has a good effect on symptomatic nephroptosis. The two stitches of suture between the upper pole of the dorsal kidney and the lumbar fascia show convenient operation, less damage and faster postoperative recovery, which are better than open surgery.

\section{Keywords}

Nephroptosis, Retroperitoneoscopic, Nephropexy

\section{Introduction}

Nephroptosis, a rare urological disease, is defined as significant downward displacement of the kidney $(>5 \mathrm{~cm}$, or two vertebral bodies) [1], as the patient moves from the supine to orthostatic position. It often occurs in young women, mostly in the right kidney [2] [3]. With the development of minimally invasive urological surgery, scholars have tried to apply minimally invasive laparoscopic surgery for symptomatic nephroptosis and obtained a better therapeutic effect. Laparoscopic nephropexy has become the preferred surgical approach for the treatment of nephroptosis in our hospital. This paper discusses indications, skills and treatment effects of laparoscopic nephropexy, as reported below.

\section{Patients and Methods}

From May 1990 to October 2013, 45 patients with nephroptosis were treated in our hospital. Among them, 25 patients underwent nephropexy (open surgery group), the other 20 patients underwent retroperitoneal laparoscopic nephropexy (laparoscopic surgery group). In open surgery group, there were 24 females and 1 male, aged 20 - 35 years, BMI was $\left(15.4-18 \mathrm{~kg} / \mathrm{m}^{2}\right) 16.77 \pm 0.80 \mathrm{~kg} / \mathrm{m}^{2}$. In laparoscopic surgery group, there were $19 \mathrm{fe}-$ males and 1 male, aged 20 - 35 years, BMI was $\left(15.4-18 \mathrm{~kg} / \mathrm{m}^{2}\right) 16.73 \pm 0.78 \mathrm{~kg} / \mathrm{m}^{2}$. All of them with nephroptosis of the right kidney were combined with lower back pain or hematuria and underwent intravenous pyelography (IVP) and color ultrasound in orthostatic and supine position for a specific diagnosis. Open surgery method: Laparoscopic surgery method: After successful general anesthesia, patients laid on the uninjured side. The skin and subcutaneous tissue $(1.5 \mathrm{~cm})$ were incised at the site measuring two finger breadths from the midaxillary line along the iliac crest. Muscles and lumbodorsal fascia till retroperitoneal cavity were bluntly dissected with a large curved forceps. First, the retroperitoneal space was expanded with fingers while the peritoneum moving forward. Then, the retroperitoneal cavity was expanded using a homemade water pocket dilatation catheter, with a $10 \mathrm{~mm}$ trocar inserted in, insufflators connected and a laparoscope placed in. Under direct vision, 10 and $5 \mathrm{~mm}$ trocars were placed below the costal margin on posterior axillary line, below the costal margin on posterior axillary line and at $2 \mathrm{~mm}$ above the anterior superior iliac spine respectively. The perirenal fascia was opened from the site below the diaphragm to the iliac fossa. The dorsal peritoneum and the lower pole of the kidney were fully dissociated while keeping fibrous tissue of the upper pole. On the dorsolateral upper pole, the kidney was fixed on the lumbar fascia for two stitches with a 2 - 0 absorbable suture, without indwelling drainage tube. All patients were in bed for one week. During reexamination three months after surgery, patient prognosis was assessed by B-mode ultrasound in orthostatic and supine position.

\section{Results}

BMI in open surgery group was $16.77 \pm 0.80 \mathrm{~kg} / \mathrm{m}^{2}$, BMI in laparoscopic surgery group was $16.73 \pm 0.78 \mathrm{~kg} / \mathrm{m}^{2}$, $P>0.05$ showed no statistical difference; the operation time in open surgery group was $70.96 \pm 10.61$ min, that in laparoscopic surgery group was $34.65 \pm 4.87 \mathrm{~min}, P<0.001$ showed highly statistical significance; the bleeding amount in open surgery group was $20.65 \pm 6.48 \mathrm{ml}$, that in laparoscopic surgery group was $4.85 \pm 1.63$ $\mathrm{ml}, P<0.001$ showed highly statistical significance; the postoperative hospital stay in open surgery group was 
$7.54 \pm 1.28 \mathrm{~d}$, that in laparoscopic surgery group was $7 \mathrm{~d}, P>0.05$ showed no statistical difference. In open surgery group, four patients had wound infection which delayed the healing, and the wound complication rate was $16 \%(4 / 25)$. In laparoscopic surgery group, wound complications did not appear, the incidence was $0 \%, \mathrm{X}^{2}$ $=1.8144, P>0.05$ showed no statistical difference. The mean follow-up visit lasted 1.5 years after surgery (3 months to 2 years), B-mode ultrasound in orthostatic and supine position showed kidneys were in the normal position. Compared with those before surgery, postoperative uncomfortable symptoms completely disappeared in all patients.

\section{Discussion}

Nephroptosis is a relatively rare urological disease. Patients (mostly 20 - 40-year lanky young women) have atypical symptoms. It often presents on the right side. About $10 \%$ of the patients have uncomfortable symptoms [4], including lower back pain, sensation of heaviness and distension, nausea, vomiting, hematuria and recurrent urinary tract infections. A small number of patients combine with urinary stones and hypertension [5]. The most serious complication of nephroptosis is Dietl's crisis, whose clinical manifestations include tachycardia and loss of consciousness [6]. The specific mechanism of nephroptosis symptoms remains unclear. Some views show that it may be associated with the traction of the vascular pedicle and the intestinal tract caused by excessive activity of the kidney [7]. There are more than 170 kinds of surgical approaches. In 1881, Eugen Hahn successfully conducted nephropexy for the patient with nephroptosis for the first time. He sutured the renal capsule to fix it on the wound edge of the waist. Afterwards, George Edebohls improved surgical approaches, promoting the nephropexy for nephroptosis. In 1993, Urban first reported nephropexy had been completed by minimally invasive laparoscopic surgery, better solving the problem of large trauma caused by open surgery. Dougall et al. [8] believe though the kidney suspension under laparoscope has a longer operative time, it presents less postoperative pain and faster recovery, about $80 \%$ of patients with low back pain and other symptoms can be improved, and more than three years of follow-up visits show a stable effect. In 2005, Wyler et al. [7] reported the suspension of the upper, middle and lower pole of the kidney and the psoas major under laparoscope for the treatment of 12 patients with symptomatic nephroptosis. The mean operative time was $91 \mathrm{~min}$, the bleeding amount was $<50 \mathrm{ml}$, the average follow-up time was 3 - 4 years. It has a good effect. Urography after surgery shows the position of the affected kidney has been corrected, symptoms of nine patients achieve full remission, two achieve partial remission, and one shows a poor surgical efficacy. Plas et al. [9] reported complications after laparoscopic nephropexy (8\%) were significantly lower than those after open surgery (33\%). Dimitri et al. [10] reported the three-hole method through retroperitoneal approach for treating one female patient with nephroptosis was satisfactory. Golab et al. [11] reported the 2-point renal fixation on 21 female patients with nephroptosis by retroperitoneal approach obtained a good effect.

In recent years, laparoscopic nephropexy for the treatment of nephroptosis is widely recognized both at home and abroad. However, operative details have not been unified. Currently, approaches for the treatment of symptomatic nephroptosis are still controversial, which are related to habits and experiences of doctors, hospital equipments and severity of nephroptosis. But our studies show that compared with open surgery, the operation time and intraoperative bleeding amount are significantly reduced using single fixation of upper pole of kidney by retroperitoneal laparoscope (Table 1), indicating high statistical significance. Although the wound complication rate and postoperative hospital stay have no statistical difference (Table 1 and Table 2), the author believes firm conclusions can be drawn only after a greater sample size of prospective controlled studies. The suture only needs to be conducted on the upper pole of the kidney for two stitches with 2 - 0 absorbable suture after the dissociation of the perirenal fascia. Therefore, compared with the respective suture on the upper, middle and lower pole of the kidney reported in the literature, its operation time is significantly shorter, and the operation is simpler. It can be seen from follow-up visits of our hospital that treatment effects are satisfactory.

Table 1. Comparisons between laparoscopic surgery group and open surgery group.

\begin{tabular}{ccccc}
\hline & BMI & Operation time & $\begin{array}{c}\text { Intraoperative } \\
\text { bleeding amount }\end{array}$ & $\begin{array}{c}\text { Postoperative } \\
\text { hospital stay }\end{array}$ \\
\hline Laparoscopic surgery group & $16.73 \pm 0.78 \mathrm{~kg} / \mathrm{m}^{2}$ & $34.65 \pm 4.87 \mathrm{~min}$ & $4.85 \pm 1.63 \mathrm{ml}$ & $7 \mathrm{~d}$ \\
Open surgery group & $16.77 \pm 0.80 \mathrm{~kg} / \mathrm{m}^{2}$ & $70.96 \pm 10.61 \mathrm{~min}$ & $20.65 \pm 6.48 \mathrm{ml}$ & $7.54 \pm 1.28 \mathrm{~d}$ \\
$P$ & $>0.05$ & $<0.001$ & $<0.001$ & $>0.05$ \\
\hline
\end{tabular}


Table 2. Comparison of the wound complication rate between two groups.

\begin{tabular}{cccc}
\hline Wound complications & Number of patients & Wound infection & Incidence rate \\
\hline Laparoscopic surgery group & 20 & 0 & $0 \%$ \\
Open surgery group & 25 & 4 & $16 \%$ \\
$x^{2}$ & & 1.8144 \\
$P$ & & $>0.05$ \\
\hline
\end{tabular}

\section{Conclusion}

In summary, retroperitoneal laparoscopic nephropexy has a good effect on the treatment of symptomatic nephroptosis. The two stitches of suture between the upper pole of the dorsal kidney and the lumbar fascia show convenient operation, less damage and faster postoperative recovery, which are better than open surgery. Postoperative follow-up visits show satisfactory treatment outcome.

\section{Disclosure Statement}

No competing financial interests exist.

\section{References}

[1] Barber, N.J. and Thompson, P.M. (2004) Nephropsis and Nephropexy-Hung up on the Past? European Urology, 46, 428-433. http://dx.doi.org/10.1016/j.eururo.2004.03.023

[2] Hübner, W.A., Schlarp, O., Riedl, C., et al. (2004) Laparoscopic Nephropexy Using Tension-Free Vaginal Tape for Sympomatic Nephropsis. Urology, 64, 372-374. http://dx.doi.org/10.1016/j.urology.2004.03.039

[3] Moss, S.W. (1997) Floating Kidney: A Century of Nephropsis and Nephropexy. Journal of Urology, 158, $699-702$.

[4] Golab, A., Slojewski, M., Gliniewicz, B., et al. (2009) Retroperitoneoscopic Nephropexy in the Treatment of Sympomatic Nephropsis with 2-Point Renal Fixation. Surgical Laparoscopy Endoscopy \& Percutaneous Techniques, 19, 356-359. http://dx.doi.org/10.1097/SLE.0b013e3181a86753

[5] Plas, E., Daha, K., Riedl, C.R., et al. (2001) Long-term Follow-Up after Laparoscopic Nephropexy for Sympomatic Nephropsis. Journal of Urology, 166, 449-452. http://dx.doi.org/10.1016/S0022-5347(05)65961-7

[6] Dietl, J. (1864) Wondrende Niemen und deren Einklemmung. Wiener Medizinische Wochenschrift, 14, 563 (part 1); 14, 579 (part 2); 14, 593 (part 3).

[7] Wyler, S.F. Sulser, T., Casella, R., et al. (2005) Retroperitoneoscopic Nephropexy for Sympomatic Nephropsis Using a Modified Three-Point Fixation Technique. Surgical Techniques in Urology, 66, 644-648.

[8] Dougall, E.M., Afane, J.S., Dunn, M.D., et al. (2000) Laparoscopic Nephropexy Long-Term Fellow-Up-Wasington University Experience[J]. Journal of Endourology, 14, 247-250. http://dx.doi.org/10.1089/end.2000.14.247

[9] Has, E., Daha, K., Riedl, C.R., et al. (2001) Long-Term Followup after Laparoscopic Nephropexy for Symptomatic Nephroptosis[J]. The Journal of Urology, 166, 449-452. http://dx.doi.org/10.1016/S0022-5347(05)65961-7

[10] Dimitfi, C., Thierry, D., Jean-Paul, A., et al. (2007) Case Report: Three-Troear Technique for Bilateral Laparoscopie Nephropexy[J]. Journal of Endourology, 21, 59-61.

[11] Golab, A., Slojewski, M., Gliniewicz, B., et al. (2009) Retroperitoneoscopic Nephropexy in the Treatment of Symptomatic Nephroptosis with 2-Point Renal Fixation[J]. Surgical Laparoscopy Endoscopy \& Percutaneous Techniques, 19, 356-359. http://dx.doi.org/10.1097/SLE.0b013e3181a86753 